Working Paper/Document de travail

2007-57

\title{
Uncertainty and the Specificity of Human Capital
}

by Martin Gervais, Igor Livshits, and Césaire Meh 
Bank of Canada Working Paper 2007-57

December 2007

\title{
Uncertainty and the Specificity of Human Capital
}

\author{
by \\ Martin Gervais ${ }^{1}$, Igor Livshits ${ }^{2}$, and Césaire $\mathrm{Meh}^{3}$ \\ ${ }^{1}$ University of Southampton \\ Southampton S017 1BJ, United Kingdom \\ 2University of Western Ontario \\ London, Ontario, Canada N6A 5B8 \\ and CIAR \\ ${ }^{3}$ Monetary and Financial Analysis Department \\ Bank of Canada \\ Ottawa, Ontario, Canada K1A 0G9 \\ cmeh@bankofcanada.ca
}

Bank of Canada working papers are theoretical or empirical works-in-progress on subjects in economics and finance. The views expressed in this paper are those of the authors.

No responsibility for them should be attributed to the Bank of Canada. 


\section{Acknowledgements}

We would like to thank Wouter den Haan, Allen Head, Ed Nosal, three anonymous referees, and participants at various conferences and institutions for valuable feedback. Nicolas Raymond provided valuable research assistance. Gervais gratefully acknowledges financial support from SSHCR. Livshits gratefully acknowledges financial support from the Arts, Humanities and Social Sciences Fund at UWO. Gervais and Livshits gratefully acknowledges financial support from the

CIBC human capital and productivity project and the EPRI, both located at the University of Western Ontario. 


\begin{abstract}
This paper studies the choice between general and specific human capital. A trade-off arises because general human capital, while less productive, can easily be reallocated across firms. Accordingly, the fraction of individuals with specific human capital depends on the amount of uncertainty in the economy. Our model implies that while economies with more specific human capital tend to be more productive, they also tend to be more vulnerable to turbulence. As such, our theory sheds some light on the experience of Japan, where human capital is notoriously specific: while Japan benefited from this predominately specific labor force in tranquil times, this specificity may also have been at the heart of its prolonged stagnation.
\end{abstract}

JEL classification: J24; J41; J62; D92

Bank classification: Economic Models

\title{
Résumé
}

L'étude porte sur le choix à opérer entre capital humain général et spécifique. Ce choix implique un arbitrage du fait que le capital humain général, bien que moins productif, peut être facilement transféré d'une entreprise à une autre. Par conséquent, la proportion des travailleurs ayant acquis un capital humain spécifique dépend du degré d'incertitude au sein de l'économie. Le modèle des auteurs indique que les économies plus riches en capital humain spécifique sont généralement plus productives, mais qu'elles ont aussi tendance à être plus vulnérables aux turbulences. Leur théorie permet d'éclairer l'expérience du Japon, pays notoirement connu pour son capital humain spécifique. En effet, si ce dernier a été profitable au Japon durant les périodes calmes, il peut aussi avoir contribué à la stagnation prolongée qu'a connue le pays.

Classification JEL : J24; J41; J62; D92

Classification de la Banque : Modèles économiques 


\section{Introduction}

This paper provides a simple theory of the choice between general and specific human capital. Our theory is based on a trade-off between productivity and the ability to reallocate human capital ex post: specific human capital is more productive than general human capital, but, unlike general human capital, it cannot be reallocated across firms. Hence, the determining factor for the choice of human capital is the extent of uncertainty about future productivity that firms and workers face when making investment decisions: economies with lower such uncertainty tend to have more workers with specific human capital, and thus tend to be more productive. However, economies with more specific human capital tend to be more vulnerable to shocks due to the inherent difficulty in reallocating such capital.

Our theory provides a coherent, though stylized, view of the Japanese economic experience since the 1950's, which can be loosely characterized as a long period of success followed by a prolonged stagnation. Our model attributes the first phase to the predominance of specific human capital in Japan, a fact well documented by ?. We then appeal to the recent increase in economic volatility, a phenomenon which Ljungqvist and Sargent (1998) refer to as turbulence, as the trigger and to the composition of the Japanese labor force as the driving force behind the recent Japanese economic experience. ${ }^{1}$ A lack of reallocation of labor of the kind that our model generates following a turbulence shock has long been suggested as an important source of Japan's stagnation (e.g. see Higuchi and Hashimoto (2004) and Kawamoto (2004)). Unlike most proposed explanations, our theory generates a prolong stagnation without relying on any inefficiencies. ${ }^{2}$

The environment we consider is an overlapping generations model where workers accumulate human capital when young, work when middle-aged, and retire when old. Cohorts of firms (or projects) are clearly identified with generations of workers. Upon paying a fixed cost of entry, firms receive a signal (good or bad) about their future productivity and hire young workers accordingly: firms who expect to be more

\footnotetext{
${ }^{1}$ See Comin and Philippon (2005) for empirical evidence on turbulence and increased volatility at the firm level observed in the last 20 years or so across many countries.

${ }^{2}$ See Hoshi and Kashyap (2004) and Porter and Sakakibara (2004) for a review. Coleman (2005)'s theory, which revolves around the emergence of China as a major competitor for Japan, is an exception.
} 
productive hire more specific human capital. Firms are only productive during the second period of their existence, as are their workers. At the beginning of that second period, firms realize their level of productivity (high or low) and may alter the amount of generalists used in production if desired.

Firms and workers in our environment sign long-term employment contracts. This market arrangement is essential since firms with good signals who realize a low productivity level end up with more specialists than they would like. Consequently, firms with unexpectedly low productivity would like to dispose of some of their workers who have acquired specific human capital. Clearly, these long-term contracts would be meaningless without commitment, not only from firms, but also from financial intermediaries (insurers) who end up bailing out firms (and workers) with unexpectedly low realized productivity.

In this model, ex ante idiosyncratic uncertainty determines the allocation of human capital investment. Three types of equilibria may emerge in the model, depending on the expected productivity level of firms with good or bad signals, as well as the relative productivity of specific versus general human capital. The entire equilibrium path for all cases is fully characterized. A key result is that output is higher in economies where signals are more informative. Intuitively, this is true because human capital is better allocated ex post in economies with more precise signals. We also show that under certain conditions, firm-specific human capital is more predominant in economies where signals are more precise.

We use the model to study the impact of turbulence. We model turbulence as a state of the world in which signals carry no information, so that firms with good and bad signals are equally likely to receive a high productivity level. As the precision of signals changes, however, we keep the fraction of firms with high productivity constant, so that in a well defined sense the aggregate technology set remains unchanged. Accordingly, turbulence has no impact in economies where all individuals acquire general human capital. We show that a regime switch from tranquil to turbulent times sends the economy on a smooth path towards a steady state with lower output. The size of the total fall in output during the transition depends on the precision of signals in tranquil times: since output is increasing in the precision of signals, the fall in output is increasing in the precision of signal in tranquil times. 
We also study the effects of unexpected transient turbulence. We show that the fall in output during the period of the shock is increasing in the expected precision of signals, regardless of whether the economy is in or out of steady state. While the immediate impact of a transient shock is due to the misallocation of labor, its persistence is due to the lower number of entering firms, which produces less output, and so on. ${ }^{3}$ Under certain conditions, we show that economies with more specific human capital are more productive but also more vulnerable to turbulence. As such, our model is consistent with the broad observation that Japan's economy prospered prior to the 1980's, but suffered tremendously from the ensuing increase in economic volatility.

Notice that a transient turbulence shock in our economy produces a prolonged recession without any changes in productivity, as the aggregate technology set remains unchanged by construction. Interestingly, however, the low level of output would conventionally show up as low measured productivity, which Hayashi and Prescott (2002) argue was the main cause of Japan's stagnation. However, Kawamoto (2004) finds little evidence of a significant decline in the pace of technological progress in the 1990's once he controls for various factors, including a reallocation effect. Indeed, Kawamoto argues that the gap between measured productivity and 'true' technology is considerably higher in the 1990's than in the previous decades.

This paper is related to recent work by Ljungqvist and Sargent (1998, 2004), who argue that the interaction of shocks and institutions can reconcile the European and U.S. unemployment divergence in the last two decades together with the fact that European labor market institutions have been in place since World War II. The central feature of their work is that the human capital of displaced workers is more likely to deteriorate in turbulent times. ${ }^{4,5}$ Although the specificity of human capital is key to

\footnotetext{
${ }^{3}$ Interestingly, such turbulence shocks generate an increase in transfers from financial intermediaries to unproductive firms, reminiscent of what Caballero et al. (2005) called "zombie" lending.

${ }^{4}$ Using a job matching model with endogenous job destruction, den Haan et al. (2005) argue that if turbulence also affects the skills of workers experiencing endogenous separation, then higher turbulence leads to a reduction in unemployment, thereby reversing the results of Ljungqvist and Sargent $(1998,2004)$.

${ }^{5}$ Our concept of turbulence is closely related to that of Ljungqvist and Sargent (1998): while workers in matches that turn out to be unproductive lose their human capital in their framework, the production value of the human capital of workers in firms with ex post low productivity is low in our economy.
} 
their analysis, it is taken as exogenous in their framework. By contrast, we focus on the decision to accumulate general versus specific human capital and their allocation across firms in a model without unemployment. Our results imply that the impact of turbulence critically depends on the amount of uncertainty and the predominance of specific human capital in the economy prior to the shock.

In a context similar to that of Ljungqvist and Sargent (1998), Wasmer (2004) shows that an economy with more general human capital (U.S.) is able to adapt better to an increase in turbulence than an economy with more specific human capital (Europe). While some of our results are similar, we derive our results without appealing to frictions in the labor market, nor do we rely on exogenous government policies. Krueger and Kumar (2004) focus on the U.S.-Europe growth difference since the 1980's. They build a model of education and technology adoption to argue that the European focus on specialized, vocational education might have worked well during the 1960's and 1970's, but not as well during the subsequent information age when new technologies emerged at a more rapid pace. While the underlying economic mechanism in that paper is quite different from ours, the increased frequency of switching technologies they consider could be interpreted as one of the sources of the increase in uncertainty in our model.

The issues addressed in this paper are quite different from those in the traditional literature on investment under uncertainty (see for example Dixit and Pindyck (1994)). This literature focuses on the need/desire for insurance against idiosyncratic risk faced by investors. By contrast, we consider an environment where investors are able to completely pool idiosyncratic risk, and focus instead on the output (profit) maximizing allocation of the investment. The trade-off we capture is between higher productivity and flexibility, which arises as firms and workers choose between specific and general human capital, as in the standard theory of human capital developed by Becker (1964).

The rest of the paper is organized as follows. The next section presents the economic environment. A definition of competitive equilibrium is offered in Section 3, where we also prove the first welfare theorem and present some basic results regarding efficient and competitive equilibrium allocations in this economy. Depending on parameter values, three types of equilibria with different ex post allocation of general 
human capital may emerge. Accordingly, in Section 4 we partition the parameter space into three regions and present a general way to find the equilibrium. We also show that any economy converges at the same pace to its unique steady state, and establish important comparative static results. The impact of turbulence is discussed in Section 5, where we introduce a form of aggregate uncertainty in the model. Concluding remarks are offered in Section 6.

\section{The Environment}

We consider a closed economy populated by overlapping generations of individuals who live for 3 periods. Individuals invest in human capital when young, work when middle-aged, and retire when old. Human capital investment can be of two distinct types: general and firm-specific. While investment in specific human capital is more productive than investment in general human capital, specific human capital can only be used by the firm for which it was acquired. By contrast, general human capital is equally productive in all firms. Each period, a single perishable consumption good is produced by a continuum of firms using human capital as the only input. For convenience, we assume that cohorts of firms correspond with cohorts of workers. Upon paying a fixed cost of entry, firms draw a signal about their second-period productivity level. Using that information, they choose how many young workers to hire and what type of human capital to employ. At the beginning of the second period, the productivity of the firm is realized, the firm adjusts its labor force if desired, and production takes place.

\section{$2.1 \quad$ Individuals}

There is a continuum (of measure one) of individuals born every period indexed by $i \in[0,1]$. They live and consume for three periods. During their first period of life, individuals accumulate human capital which becomes productive when middle-aged and depreciates fully when old. All individuals have the same preferences represented by the utility function

$$
U\left(c^{1}, c^{2}, c^{3}\right)-v(h+g)=\ln c^{1}+\beta \ln c^{2}+\beta^{2} \ln c^{3}-\eta(h+g),
$$


where $h$ and $g$ respectively represent specific and general human capital acquired when young, $c^{j}$ represents consumption at age $j, 0<\beta<1$ is a discount factor and $\eta$ is the utility cost of accumulating 1 unit of human capital. Although individuals can acquire both general and specific human capital when young, they can only supply labor to a single firm when middle-aged.

There are two generations of individuals already alive at the beginning of period 0 : there is a measure 1 of old individuals, who are entitled to $c_{0}^{3}$ units of consumption, and a measure 1 of middle-aged individuals with some arbitrary stocks of specific and general human capital, who are entitled to $W_{0}^{2}=Y_{0}-c_{0}^{3}$, where $Y_{0}$ is the total output in the economy. As far as the future evolution of the economy is concerned, the initial condition is fully summarized by the disposable income of the initial middleaged individuals $W_{0}^{2}$.

\section{$2.2 \quad$ Firms}

Each period a measure of ex-ante identical potential entrants (firms or projects) are born. Should they choose to enter, they must pay a fixed cost $\phi$. Life cycle of firms coincides with the life cycle of individuals born in the same period. Newly entering (young) firms draw idiosyncratic signals $s \in\{g ; b\}$ about their future productivity and hire young workers. In the second period of their life, the firms realize their productivity level $Z$, hire additional general human capital if needed, and produce. In the following period, the firms become inactive (die). We denote $\mu_{t}$ the measure of firms entering in period $t-1$, as these firms will produce in period $t$. In equilibrium, the measure of firms entering in any given period is determined by a free-entry condition.

We denote $\rho$ the fraction of young firms who draw the good signal $g$. After drawing their individual signal, each young firm decides how many young workers to hire, and signs binding contracts with these workers. Each contract specifies the type and amount of human capital to be acquired by the worker as well as payments to the worker in the current and future periods. The labor market of young workers is competitive.

The actual productivity levels, drawn at the beginning of the second period $(t)$, 
can take on two values: $Z \in\left\{Z_{H}, Z_{L}\right\}$, where $Z_{H}>Z_{L}>0$. The probability that a firm with signal $s$ draws high productivity is denoted $\pi_{s}$, with $\pi_{g} \geqslant \pi_{b}>0$. Ex post, the fraction of firms with high productivity is $\bar{\pi}=\rho \pi_{g}+(1-\rho) \pi_{b}$. Once a firm realizes its productivity level $Z$, it can hire additional workers with general human capital from other firms or "lend out" its own workers. The market for middle-aged workers with general human capital is also competitive. The production function of an individual firm is:

$$
F(H, G)=Z(H+\gamma G)^{\theta}
$$

where $H$ and $G$ respectively denote total stocks of specific and general human capital employed by the firm, $\gamma \in(0,1)$ is the relative productivity of general human capital, and $\theta \in(0,1)$. This specification with $\gamma<1$ implies that firm-specific human capital is more productive than general human capital. The advantage of general human capital is that it offers firms flexibility, as workers with general human capital can be reallocated from unexpectedly unproductive firms to unexpectedly productive ones.

\subsection{Financial Intermediaries}

There are several allocation-equivalent ways to model the financial (and insurance) side of our economy. A transparent one is to think of a competitive mutual fund financed or created every period by middle-aged workers. This mutual fund pools future idiosyncratic risk and advances credit to newly created firms.

Entering firms borrow from the intermediary to pay the entry cost. Upon realizing their signal of future productivity, entering firms borrow additional funds to pay young workers they hire. Effectively, this borrowing cannot be disentangled from the insurance against future idiosyncratic productivity shocks that these young firms are purchasing. The "repayment" of these loans is contingent on the realized productivity level next period. In fact, if the dispersion of productivity levels is sufficiently large, firms could even receive further funds from the intermediary next period if their productivity level were very low relative to expectations derived from the signal. But these are financed from extraordinarily high "repayments" from the "lucky" firms and do not involve intergenerational transfers.

The ownership of firms is irrelevant since competitive entry and full insurance 
against idiosyncratic risk guarantee that their value is zero. One could thus imagine that the mutual fund effectively owns all the firms it finances and receives all their revenues less wages paid. This "ownership" features unlimited liability.

\section{Competitive Equilibria}

A natural way to decentralize efficient allocations in our environment is for new firms to write long-term contracts with their workers specifying payments for the three periods during which individuals live. Each contract is the solution to a firm's profit maximization problem subject to keeping young workers' utility above some reservation value. As will become clear in the next section, the model is much more tractable under an equivalent representation. This representation uses the fact that firms know precisely the way in which workers want to distribute their resources over their life-time. It follows that firms could equivalently offer workers a single wage payment in either period of a worker's life and let the worker decide on its distribution across periods. In the definition of a competitive equilibrium below, we therefore assume without loss of generality that firms only offer a second period wage to young workers they hire. We denote $w_{t}^{H}$ the wage of a worker born in period $t-1$ who accumulates specific human capital and $w_{t}^{G}$ that of a worker who accumulates general human capital.

In the environment described above, firms and workers sign long-term contracts. This market arrangement is important to support specific human capital in equilibrium. These long-term contracts, however, would be meaningless without commitment. In particular, a severe hold-up problem emerges when firms cannot commit to these contracts, which result in an equilibrium without any specific human capital. In addition, commitment from financial intermediaries (insurers) is also essential, as they end up bailing out firms (and workers) with low realized productivity. ${ }^{6}$

\footnotetext{
${ }^{6}$ See Gervais and Livshits (2007) for a detailed analysis of a similar environment with various degrees of commitment.
} 


\subsection{Definition}

To simplify the exposition, the definition of the competitive equilibrium that follows uses the result of Proposition 1 which states that all individuals fully specialize either in specific or general human capital. This implies that the aggregate supply of specific and general human capital respectively are

$$
\begin{aligned}
\mathcal{H}_{t} & =\int h_{t}(i) d i, \\
\mathcal{G}_{t} & =\int g_{t}(i) d i .
\end{aligned}
$$

A Competitive Equilibrium in this environment consists of sequences of prices $\left\{w_{t}^{H}, w_{t}^{G}, r_{t}\right\}$, allocation functions for individuals $\left\{c_{t-1}^{1}(i), c_{t}^{2}(i), c_{t+1}^{3}(i), h_{t}(i), g_{t}(i)\right\}$ and for firms $\left\{H_{t}(s), \Pi_{t}(s), G_{t}(Z, H), R_{t}(Z, H)\right\}$, and aggregates $\left\{\mu_{t}, Y_{t}, \mathcal{G}_{t}, \mathcal{H}_{t}\right\}$, such that

1. given prices, individuals' allocations maximize utility subject to their (maximized) present-value budget constraint: ${ }^{7}$

$$
\begin{aligned}
& \max _{c, h, g}\left[\ln c_{t-1}^{1}+\beta \ln c_{t}^{2}+\beta^{2} \ln c_{t+1}^{3}-\eta\left(h_{t}+g_{t}\right)\right] \\
& \text { s.t. } c_{t-1}^{1}\left(1+r_{t}\right)+c_{t}^{2}+\frac{c_{t+1}^{3}}{1+r_{t+1}} \leqslant \max \left\{w_{t}^{H} h_{t}, w_{t}^{G} g_{t}\right\}
\end{aligned}
$$

2. given prices and stock of specific human capital, $G_{t}(Z, H)$ maximizes profits in the second period:

$$
R_{t}(Z, H) \equiv \max _{G \geqslant 0}\left[Z(H+\gamma G)^{\theta}-w_{t}^{G} G\right]
$$

3. given prices, signal and $R_{t}(Z, H), H_{t}(s)$ maximizes expected present value of profits:

$$
\Pi_{t}(s) \equiv \max _{H}\left[\mathrm{E}\left[R_{t}(Z, H) \mid s\right]-w_{t}^{H} H\right]
$$

4. expected profits of entrants are zero:

$$
\frac{\mathrm{E}\left[\Pi_{t}(s)\right]}{1+r_{t}}=\phi
$$

\footnotetext{
${ }^{7}$ The right-hand side of the budget constraint incorporates the result that individuals accumulate either only specific or only general human capital
} 
5. markets clear:

$$
\begin{aligned}
& \mathcal{G}_{t}=\mu_{t}\left\{\rho\left[\pi_{g} G_{t}\left(Z_{H}, H_{t}(g)\right)+\left(1-\pi_{g}\right) G_{t}\left(Z_{L}, H_{t}(g)\right)\right]+\right. \\
&\left.(1-\rho)\left[\pi_{b} G_{t}\left(Z_{H}, H_{t}(b)\right)+\left(1-\pi_{b}\right) G_{t}\left(Z_{L}, H_{t}(b)\right)\right]\right\} \\
& \mathcal{H}_{t}=\mu_{t}\left[\rho H_{t}(g)+(1-\rho) H_{t}(b)\right] \\
& \frac{c_{t+1}^{3}}{1+r_{t+1}}=\mu_{t+1} \phi+c_{t}^{1} \\
& c_{t}^{1}+c_{t}^{2}+c_{t}^{3}+\phi \mu_{t+1}=Y_{t}
\end{aligned}
$$

where aggregate output in period $t$ is given by

$$
\begin{gathered}
Y_{t}=\mu_{t}\left[\rho\left(\pi_{g} Z_{H}\left(H_{t}(g)+\gamma G_{t}\left(Z_{H}, H_{t}(g)\right)\right)^{\theta}+\left(1-\pi_{g}\right) Z_{L}\left(H_{t}(g)+\gamma G_{t}\left(Z_{L}, H_{t}(g)\right)\right)^{\theta}\right)\right. \\
\left.+(1-\rho)\left(\pi_{b} Z_{H}\left(H_{t}(b)+\gamma G_{t}\left(Z_{H}, H_{t}(b)\right)\right)^{\theta}+\left(1-\pi_{b}\right) Z_{L}\left(H_{t}(b)+\gamma G_{t}\left(Z_{L}, H_{t}(b)\right)\right)^{\theta}\right)\right] .
\end{gathered}
$$

A few notes are in order. First, since generalists can be freely re-allocated when middle-aged, their distribution across firms when young is irrelevant. Second, whereas the two labor market clearing conditions (equations (4) and (5)) and the goods market clearing condition (equation (7)) are self-explanatory, the savings market clearing condition (6) requires some explanation. This condition states that consumption of the old must have been saved in the previous period as this is the only source of income for old individuals. In turn, savings are used either to finance entering firms or to provide young individuals with consumption.

\subsection{Some Basic Results}

Before proceeding to the analysis and implications of the model, we establish some basic results that prove useful in the analysis.

First, because of the linearity of the utility function in human capital, all individuals will accumulate the same amount of human capital, given by $\left(1+\beta+\beta^{2}\right) / \eta$. We thus normalize $\eta=\left(1+\beta+\beta^{2}\right)$, so that individuals will accumulate one unit of 
human capital. ${ }^{8}$ Second, we state without a formal proof that whenever both general and firm-specific human capital is accumulated in equilibrium, young workers have to be indifferent between the two types of human capital. It follows that they will receive the same wage regardless of the type of labor services they supply, i.e. $w_{t}^{H}=w_{t}^{G}=w_{t}$.

Our next two results can be stated either in terms of competitive equilibrium or efficient allocations. The first result establishes that all individuals fully specialize either in specific or general human capital. ${ }^{9}$ The second result establishes that our economy always features a positive measure of individuals with firm-specific human capital. We then show that the first welfare theorem holds in our environment.

Proposition 1 Neither efficient nor competitive equilibrium allocations can feature a positive measure of individuals acquiring both specific and general human capital.

Proof. Suppose, by contradiction, that in an efficient (or competitive equilibrium) allocation a firm $i$ hires a positive measure $\lambda$ of individuals who make fraction $\kappa$ of their human capital investment general and fraction $(1-\kappa)$ specific. Consider an alternative allocation where firm $i$ hires $\kappa \lambda$ individuals acquire only general human capital and the remaining $(1-\kappa) \lambda$ only acquire specific human capital. The alternative allocation results in weakly greater output for all productivity levels, while keeping the cost of acquiring human capital constant. The output of the two allocations is the same if there is no ex post reallocation, and the output of the alternative allocation is greater if some of the workers under consideration are reallocated to other firms. When workers with general human capital are reallocated ( $\kappa \lambda$ of them), there is now $(1-\kappa) \lambda$ workers with specific human capital who remain productively employed in firm $i$. That portion of the human capital stock was lost during reallocation in the original allocation. Note further that the event in which the reallocation occurs has strictly positive probability, since otherwise firm $i$ would make all its employees obtain specific human capital only. It follows that the alternative allocation always delivers at least as much output as the original, and delivers strictly more output (revenue)

\footnotetext{
${ }^{8}$ This essentially amounts to normalizing the unit of time. More precisely, if we start with an equilibrium under parameters $\left(\eta, Z_{L}, Z_{H}\right)$, then the same equilibrium obtains under parameters $\left(\tilde{\eta}, \tilde{Z}_{L}, \tilde{Z}_{H}\right)$, where $\tilde{\eta}=\lambda \eta, \tilde{Z}_{L}=\lambda^{\theta} Z_{L}$, and $\tilde{Z}_{H}=\lambda^{\theta} Z_{H}$.

${ }^{9}$ Recall that we used this result to simplify the statement of the labor market clearing conditions in the definition of competitive equilibrium.
} 
with strictly positive probability, while keeping the costs constant. ${ }^{10}$ This implies that the original allocation could not have been efficient nor profit-maximizing since the rental price of general human capital is strictly positive.

Proposition 2 The measure of individuals with specific human capital is strictly positive in any efficient or competitive equilibrium allocation.

Proof. This follows directly from the fact that once all firms have received their idiosyncratic productivity shock, even the firm with the smallest productivity shock will be operating and so would hire a positive amount of specific human capital. In other words, even if a firm knew for sure that its productivity level tomorrow will be low, it would still want to hire workers with specific human capital since they are more productive and no more expensive than generalists. ${ }^{11}$

Our next Proposition shows that the First Welfare theorem holds in this economy. The following Lemma, which shows that unbounded growth cannot by sustained in our economy, will be useful to prove the first welfare theorem.

Lemma 1 Feasible allocations in which consumption of successive generations grows without bound feature utility of successive generations that declines without bound.

Proof. We start by establishing an upper bound on output that can be produced given a measure of firms $\mu$ and an aggregate stock of human capital $\mathcal{H}$ :

$$
Y<\mu Z_{H}\left(\frac{\mathcal{H}}{\mu}\right)^{\theta}
$$

Next, note that if the entire output of the economy is invested in period $t-1$, i.e. $\mu_{t}=\frac{Y_{t-1}}{\phi}$, then the maximum achievable output in period $t$ is given by

$$
Y_{t}=Y_{t-1}^{1-\theta}\left(\frac{Z_{H}}{\phi^{1-\theta}}\right) \mathcal{H}_{t}^{\theta}
$$

If the aggregate stock of human capital is fixed at $\bar{H}$, the previous equation provides a bound for output in the long run. To see this, define $\bar{Y}$ as long run output from

\footnotetext{
${ }^{10}$ Note that if $Z_{L}=0$, both allocations produce the same output as there is no gain in keeping individuals with specific human capital in unproductive firms.

${ }^{11}$ Note that this proposition need not hold if $Z_{L}=0$.
} 
the previous equation:

$$
\bar{Y}=\left(\frac{Z_{H}}{\phi^{1-\theta}}\right)^{1 / \theta} \bar{H}
$$

Note that if $Y_{t-1}>\bar{Y}$, then $Y_{t}<Y_{t-1}$. It follows that for any fixed stock of human capital $\bar{H}, Y_{t}<\max \left\{Y_{0}, \bar{Y}\right\}$ for all $t>0$. If output is to exceed some constant $B$ in the long run, then, the stock of human capital must exceed

$$
\bar{H}(B)=\left(\frac{\phi^{1-\theta}}{Z_{H}}\right)^{1 / \theta} B
$$

We now construct a very loose upper bound on the utility of a generation by assuming that individuals consume the entire amount $B$ in every period of their life, but only produce it once. ${ }^{12}$ This delivers the upper bound

$$
\bar{U}(B)=\left(1+\beta+\beta^{2}\right) \ln B-\eta\left(\frac{\phi^{1-\theta}}{Z_{H}}\right)^{1 / \theta} B .
$$

This upper bound on utility $\bar{U}(B)$ goes to $-\infty$ as $B$ increases. It follows that if consumption is unbounded ( $B$ above goes to $\infty$ ), the utility of a generation cannot be bounded below.

Proposition 3 Competitive equilibrium allocations are efficient.

Proof. Suppose, by contradiction, that there exists a feasible allocation $\widehat{c}_{0}^{3}$, $\left(\widehat{c}_{0}^{2}, \widehat{c}_{1}^{3}, h_{0}, g_{0}\right), \quad\left\{\widehat{c}_{t-1}^{1}, \widehat{c}_{t}^{2}, \widehat{c}_{t+1}^{3}, \widehat{h}_{t}, \widehat{g}_{t}\right\}_{t=1}^{\infty} \quad$ for $\quad$ households, $\quad \widehat{G}_{0}(Z, H), H_{0}(s)$, $\left\{\widehat{H}_{t}(s), \widehat{G}_{t}(Z, H)\right\}_{t=1}^{\infty}$ for firms, and aggregates $\left(\mu_{0}, \widehat{Y}_{0}, \mathcal{H}_{0}, \mathcal{G}_{0}\right), \quad\left\{\widehat{\mu}_{t}, \widehat{Y}_{t}, \widehat{\mathcal{H}}_{t}, \widehat{\mathcal{G}}_{t}\right\}_{t=1}^{\infty}$, which Pareto dominates the competitive equilibrium allocation. Note that if there exists such an allocation which makes a positive measure of individuals in some generation better off, then there also exists an allocation that makes everyone in that generation better off. Accordingly, for the purposes of this proof we will only consider such "equal treatment" allocations. We then simply have $\ln \widehat{c}_{0}^{3} \geqslant \ln c_{0}^{3}$, $\ln \widehat{c}_{0}^{2}+\beta \ln \widehat{c}_{1}^{3} \geqslant \ln c_{0}^{2}+\beta \ln c_{1}^{3}$, and $u_{t}\left(\widehat{c}, \widehat{h}_{t}+\widehat{g}_{t}\right) \geqslant u_{t}\left(c, h_{t}+g_{t}\right)$ for all $t \geqslant 1$, with strict inequality for at least one generation. Since preferences satisfy local nonsatiation, it follows from the definition of competitive equilibrium that $\widehat{c}_{0}^{3} \geqslant c_{0}^{3}$, $\widehat{c}_{0}^{2}+\frac{\widehat{c}_{1}^{3}}{1+r_{t+1}} \geqslant W_{0}^{2}$, and $\widehat{c}_{t-1}^{1}\left(1+r_{t}\right)+\widehat{c}_{t}^{2}+\frac{\widehat{c}_{t+1}^{3}}{1+r_{t+1}} \geqslant w_{t}^{H} \widehat{h}_{t}+w_{t}^{G} \widehat{g}_{t}$ for all $t \geqslant 1$, with

\footnotetext{
${ }^{12} \mathrm{We}$ are in fact allowing the entire output to be both consumed and saved.
} 
strict inequality for at least one generation. Multiplying the latter inequalities by $\prod_{\tau=1}^{t} \frac{1}{1+r_{\tau}}$ and summing over all generations, we get

$$
\sum_{t=0}^{\infty}\left(\prod_{\tau=1}^{t} \frac{1}{1+r_{\tau}}\right)\left(\widehat{c}_{t}^{1}+\widehat{c}_{t}^{2}+\widehat{c}_{t}^{3}\right)>c_{0}^{3}+W_{0}^{2}+\sum_{t=1}^{\infty}\left(\prod_{\tau=1}^{t} \frac{1}{1+r_{\tau}}\right)\left(w_{t}^{H} \widehat{\mathcal{H}}_{t}+w_{t}^{G} \widehat{\mathcal{G}}_{t}\right)
$$

as long as the summations are finite. To see that they are, first note that Lemma 1 implies that the economy cannot sustain unbounded growth, so that $\left(\widehat{c}_{t}^{1}+\widehat{c}_{t}^{2}+\widehat{c}_{t}^{3}\right)$ is bounded. Furthermore, as will be shown in the next Section (see Proposition 4), the competitive equilibrium converges to a steady state. To establish that the summation on the left-hand-side is finite, then, we simply need to show that the interest rate is strictly positive in that steady state. To see this, note that consumers with logarithmic utility functions allocate income across periods in fixed proportions. If we let $W_{s s}$ denote the steady state lifetime wealth of individuals in terms of young-age consumption goods, then

$$
\begin{aligned}
\frac{c_{s s}^{3}}{\left(1+r_{s s}\right)^{2}} & =\frac{\beta^{2}}{1+\beta+\beta^{2}} W_{s s} \\
c_{s s}^{1} & =\frac{1}{1+\beta+\beta^{2}} W_{s s} .
\end{aligned}
$$

These expressions imply that market clearing condition (6) cannot hold in steady state unless the interest rate is strictly positive in that steady state.

We now want to argue that, for all $t \geqslant 1$,

$$
\widehat{Y}_{t}-\left(w_{t}^{H} \widehat{\mathcal{H}}_{t}+w_{t}^{G} \widehat{\mathcal{G}}_{t}\right)-\widehat{\mu}_{t} \phi\left(1+r_{t}\right) \leqslant Y_{t}-\left(w_{t}^{H} \mathcal{H}+w_{t}^{G} \mathcal{G}\right)-\mu_{t} \phi\left(1+r_{t}\right)=0 .
$$

To see that, consider the period-t production-planner's problem:

$$
J_{t} \equiv \max _{\mu, H(\cdot), G(\cdot)}\left[\text { TotalOutput }_{t}-\text { TotalWages }_{t}-\phi \mu\left(1+r_{t}\right)\right]
$$

The only difference between this problem and a standard profit maximization problem 
is that the number of firms $\mu$ is now a choice variable. Formally,

$$
\begin{gathered}
J_{t} \equiv \max _{\mu, H(\cdot), G(\cdot)}\{ \\
\mu \rho\left[\pi_{g} Z_{H}\left(H(g)+\gamma G\left(Z_{H}, H(g)\right)\right)^{\theta}+\left(1-\pi_{g}\right) Z_{L}\left(H(g)+\gamma G\left(Z_{L}, H(g)\right)\right)^{\theta}\right] \\
+\mu(1-\rho)\left[\pi_{g} Z_{H}\left(H(b)+\gamma G\left(Z_{H}, H(b)\right)\right)^{\theta}+\left(1-\pi_{g}\right) Z_{L}\left(H(b)+\gamma G\left(Z_{L}, H(b)\right)\right)^{\theta}\right] \\
-\mu w_{t}^{G}\left[\rho\left(\pi_{g} G\left(Z_{H}, H(g)\right)+\left(1-\pi_{g}\right) G\left(Z_{L}, H(g)\right)\right)\right. \\
\left.+(1-\rho)\left(\pi_{b} G\left(Z_{H}, H(b)\right)+\left(1-\pi_{b}\right) G\left(Z_{L}, H(b)\right)\right)\right] \\
\left.\quad-\mu w_{t}^{H}[\rho H(g)+(1-\rho) H(b)]-\phi \mu\left(1+r_{t}\right)\right\}
\end{gathered}
$$

The first key observation here is that the choice of $\mu$ does not in any way affect the choice of human capital investment and allocation - $\mu$ simply multiplies the objective. The second key observation is that the competitive equilibrium allocation maximizes the objective with respect to $H(\cdot)$ and $G(\cdot)$, taking $\mu$ as given. Incorporating these observations, we get

$$
J_{t}=\max _{\mu} \mu\left[\max _{H(\cdot), G(\cdot)}\left(E\left[\Pi_{t}(s)\right]-\phi\left(1+r_{t}\right)\right)\right],
$$

where $E\left[\Pi_{t}(s)\right]$ is the expected profits of an entering firm in period $t-1$. The last key observation is that the maximum value of the expression in square brackets, which is achieved by the competitive equilibrium allocation, is 0 . This follows from the free entry condition (3) on firms in competitive equilibrium. It follows that no allocation can achieve higher value for problem (11) than the competitive equilibrium allocation, thereby establishing the desired result stated in equation (10).

Rearranging equation (10), we get $w_{t}^{H} \widehat{\mathcal{H}}_{t}+w_{t}^{G} \widehat{\mathcal{G}}_{t} \geqslant \widehat{Y}_{t}-\widehat{\mu}_{t} \phi\left(1+r_{t}\right)$ for all $t \geqslant 1$. Substituting this into the right-hand side of (9), and recalling that $\widehat{Y}_{0} \leqslant Y_{0}=c_{0}^{3}+W_{0}^{2}$, we obtain

$$
\sum_{t=0}^{\infty}\left(\prod_{\tau=1}^{t} \frac{1}{1+r_{\tau}}\right)\left(\widehat{c}_{t}^{1}+\widehat{c}_{t}^{2}+\widehat{c}_{t}^{3}\right)>\widehat{Y}_{0}+\sum_{t=1}^{\infty}\left(\prod_{\tau=1}^{t} \frac{1}{1+r_{\tau}}\right)\left(\widehat{Y}_{t}-\widehat{\mu}_{t} \phi\left(1+r_{t}\right)\right) .
$$

Rearranging then delivers

$$
\sum_{t=0}^{\infty}\left(\prod_{\tau=1}^{t} \frac{1}{1+r_{\tau}}\right)\left(\widehat{c}_{t}^{1}+\widehat{c}_{t}^{2}+\widehat{c}_{t}^{3}+\widehat{\mu}_{t+1} \phi\right)>\sum_{t=0}^{\infty}\left(\prod_{\tau=1}^{t} \frac{1}{1+r_{\tau}}\right) \widehat{Y}_{t}
$$


But that contradicts the feasibility of the candidate allocation, which requires that for all $t$,

$$
\widehat{c}_{t}^{1}+\widehat{c}_{t}^{2}+\widehat{c}_{t}^{3}+\phi \widehat{\mu}_{t+1} \leqslant \widehat{Y}_{t}
$$

\section{Characterizing Equilibria}

In this section we study the different types of equilibria that this economy can generate. Three types of equilibria may emerge, depending on parameter values. In the first two cases, a fraction of individuals acquire specific human capital and the rest acquire general human capital. What differentiates these two cases is whether all $e x$ post productive firms hire generalists or only those who received a bad signal ex ante hire generalists. ${ }^{13}$ A special case of an equilibrium in which all high productivity firms hire generalists is one where all individuals acquire general human capital. The last type of equilibrium is one where all individuals acquire specific human capital.

\subsection{Solving for an Equilibrium}

In Appendix $\mathrm{A}$ we show in detail how to construct the full solution to the model for each type of equilibrium. As it turns out, the general way to find a solution is common to all three types. The algorithm proceeds as follows.

At the beginning of any period $t$, the state of the economy is given by the number of firms that entered in the previous period as well as the amount of consumption that is currently promised to the old, $\left(\mu_{t}, c_{t}^{3}\right)$. We now briefly demonstrate how to obtain $\left(\mu_{t+1}, c_{t+1}^{3}\right)$ from the current state.

We show in Appendix A that independent of the type of equilibrium, the labor market clearing conditions implies that the wage rate in period $t$ is completely determined by the current measure of producing firms:

$$
w_{t}=A \theta \mu_{t}^{1-\theta}
$$

\footnotetext{
${ }^{13}$ Note that low productivity firms never hire generalists.
} 
where $A$ is a constant, the value of which depends on the type of equilibrium. Since the labor share of output is given by $\theta$, i.e. $w_{t}=\theta Y_{t}$, we can write aggregate output as a function of $\mu$ :

$$
Y_{t}=A \mu_{t}^{1-\theta}
$$

The aggregate disposable income of middle-aged individuals is given by $Y_{t}^{d} \equiv Y_{t}-$ $c_{t}^{3}$. With logarithmic utility functions, middle-aged individuals will save a constant fraction of their income, $X_{t}=\left(\frac{\beta}{1+\beta}\right) Y_{t}^{d}$, and consume the remainder, $c_{t}^{2}=\left(\frac{1}{1+\beta}\right) Y_{t}^{d}$. The market clearing condition for savings and investment then implies that

$$
X_{t}=\left(\frac{\beta}{1+\beta}\right)\left(Y_{t}-c_{t}^{3}\right)=\mu_{t+1} \phi+\frac{w_{t+1}}{\left(1+r_{t+1}\right)\left(1+\beta+\beta^{2}\right)} .
$$

In other words, the resources saved by the current middle-aged are used to pay the entry cost of firms that will produce tomorrow as well as the consumption of young individuals in period $t$, which they optimally choose to be a fraction of the wage they will receive tomorrow (see equation (6)).

Next we use the free entry condition to establish a relationship between the interest rate and the measure of entering firms. Expected profits of a firm entering at date $t$ are given by

$$
\begin{array}{r}
E\left[\Pi_{t+1}(s)\right]=\rho\left(E\left[Z_{t+1} F\left(H_{t+1}(g), G_{t+1}\right) \mid g\right]-w_{t+1}\left(H_{t+1}(g)+E\left[G_{t+1} \mid g\right]\right)\right) \\
+(1-\rho)\left(E\left[Z_{t+1} F\left(H_{t+1}(b), G_{t+1}\right) \mid b\right]-w_{t+1}\left(H_{t+1}(b)+E\left[G_{t+1} \mid b\right]\right)\right) .
\end{array}
$$

Summing over all firms and using market clearing conditions (4) and (5), we have

$$
\mu_{t+1} E\left[\Pi_{t+1}(s)\right]=Y_{t+1}-w_{t+1} .
$$

The free entry condition (3) can thus be written as

$$
\frac{Y_{t+1} / \mu_{t+1}-w_{t+1} / \mu_{t+1}}{1+r_{t+1}}=\phi,
$$

or, using (12) and (13),

$$
1+r_{t+1}=\frac{A(1-\theta)}{\phi} \mu_{t+1}^{-\theta}
$$

We can now use equation (16) together with the equation for output (13) in equation (14) to solve for the measure of firms that will be producing in period $t+1$ :

$$
\mu_{t+1}=\Lambda A \mu_{t}^{1-\theta}-\Lambda c_{t}^{3}
$$


where

$$
\Lambda=\frac{\beta}{\phi(1+\beta)}\left[1+\frac{\theta}{(1-\theta)\left(1+\beta+\beta^{2}\right)}\right]^{-1} .
$$

Finally, consumption of the old in period $t+1$ is given by the return on the period $\mathrm{t}$ savings of the middle-aged, that is,

$$
c_{t+1}^{3}=\left(\frac{\beta}{1+\beta}\right)\left(1+r_{t+1}\right)\left(Y_{t}-c_{t}^{3}\right),
$$

where $r_{t+1}$ is given by (16).

While this algorithm is independent of the type of equilibrium, the constant $A$ does depend on the the type of equilibrium under study, which itself depends on parameter values. We now partition the parameter space into three regions corresponding to each type of equilibrium.

\subsection{Types of Equilibria}

Parameter values completely determine the type of equilibrium we obtain. Let $E_{g}=E[Z \mid s=g]=\pi_{g} Z_{H}+\left(1-\pi_{g}\right) Z_{L}$ and $E_{b}=E[Z \mid s=b]=\pi_{b} Z_{H}+\left(1-\pi_{b}\right) Z_{L}$ denote the expected productivity level of a firm with a good and bad signal, respectively. We show in the Appendix that when the ratio of relative productivities is such that

$$
E_{g}<\gamma Z_{H}
$$

then the equilibrium is one where all firms with a high realized productivity level, regardless of the signal they received, hire generalists. Similarly, when the relative productivities is such that

$$
E_{b}<\gamma Z_{H} \leq E_{g},
$$

then the equilibrium is one where only firms that received a bad signal but a high realized productivity level hire generalists. Finally, if

$$
\gamma Z_{H} \leq E_{b},
$$

then all individuals will be specialists.

It should be noted that these conditions completely characterize the path of the economy, in the sense that if we start in one of these cases, the economy will remain 
in that case. ${ }^{14}$ Table 1 summarizes the types of equilibria that can occur in this economy.

Table 1: Types of Equilibria

\begin{tabular}{llc}
\hline \hline Type & Description & Condition \\
\hline Type 1: & All high productivity firms hire generalists & $E_{b}<E_{g}<\gamma Z_{H}$ \\
Type 2: & Only high productivity firms who received & $E_{b}<\gamma Z_{H} \leq E_{g}$ \\
Type 3: & All individuals are specialists & $\gamma Z_{H} \leq E_{b}<E_{g}$ \\
\hline \hline
\end{tabular}

${ }^{a}$ The case where all individuals are generalists $\left(Z_{L}=0\right)$ is a special case of Type 1 .

\subsection{Convergence}

The transitional dynamics for any type of equilibrium are very tractable. The following lemma establishes that we can take initial conditions to have the property that promised consumption to the old is a constant fraction of income, which will be useful in our next proposition.

Lemma 2 For any $\left(c_{t}^{3}, \mu_{t}\right)$, consumption promised to the old in period $t+1$ is a constant fraction of output in period $t+1$, i.e. $c_{t+1}^{3}=\alpha Y_{t+1}$.

Proof. First note that using equation (16), equation (14) implies that

$$
X_{t}=\phi \mu_{t+1}\left[1+\frac{\theta}{(1-\theta)\left(1+\beta+\beta^{2}\right)}\right] \text {. }
$$

Using (16) and the first equality in (14), we can also rewrite equation (19) as

$$
\begin{aligned}
c_{t+1}^{3} & =\left(\frac{A(1-\theta)}{\phi}\right) \mu_{t+1}^{-\theta} X_{t} \\
& =A(1-\theta)\left[1+\frac{\theta}{(1-\theta)\left(1+\beta+\beta^{2}\right)}\right] \mu_{t+1}^{1-\theta} .
\end{aligned}
$$

Finally, using (13), it follows that $c_{t+1}^{3}=\alpha Y_{t+1}$, where $0<\alpha<1$ is given by

$$
\alpha=1-\theta\left[\frac{\beta+\beta^{2}}{1+\beta+\beta^{2}}\right] \text {. }
$$

\footnotetext{
${ }^{14}$ This will not necessarily be the case in section 5 , where we introduce turbulence.
} 
Figure 1: Convergence

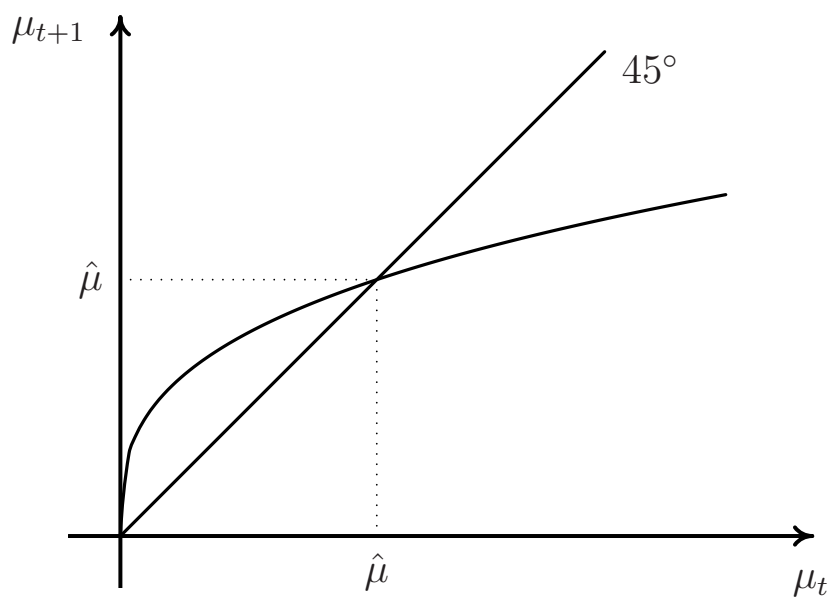

Proposition 4 Given parameter values, every equilibrium path converges to a unique steady state. The logarithmic distance of output from its steady state level is reduced by fraction $\theta$ every period.

Proof. Following Lemma 2, we can take $c_{t}^{3}=\alpha Y_{t}$. Then equations (13) and (17) imply that

$$
\mu_{t+1}=(1-\alpha) \Lambda A \mu_{t}^{1-\theta}
$$

Figure 1 plots this last equation along with the $45^{\circ}$ line. This Figure illustrates that for any $\mu_{0}>0$, the economy converges monotonically to a unique steady state labeled $\hat{\mu}$.

The steady state measure of firms and output (using equation (13)) are given by

$$
\begin{aligned}
& \hat{\mu}=(A(1-\alpha) \Lambda)^{\frac{1}{\theta}}, \\
& \hat{Y}=A^{\frac{1}{\theta}}((1-\alpha) \Lambda)^{\frac{1-\theta}{\theta}},
\end{aligned}
$$

where $\alpha$ (given by equation (23)), $\Lambda$ (given by equation (18)), and $A$ (given by equations (33)-(36) in Appendix A) are all functions of exogenous parameters. Finally, equation (13) implies that

$$
\frac{Y_{t+1}}{\hat{Y}}=\left(\frac{\mu_{t+1}}{\hat{\mu}}\right)^{1-\theta}=\left(\frac{Y_{t}}{\hat{Y}}\right)^{1-\theta} .
$$


It is interesting to note that neither $\alpha$ nor $\Lambda$ depend on any of the uncertainty parameters. It follows that the effect of uncertainty is fully captured by the constant $A$. We exploit this fact below to show that steady state output increases as signals become more informative.

\subsection{Comparative Statics}

We now establish two key results concerning the way in which output and human capital react to changes in the precision of signals. Before doing so, notice that as the precision of signals increases - $E_{b}$ decreases and $E_{g}$ increases - the Type of equilibrium may change (See Table 1): if initially we have a Type 1 or Type 3 equilibrium, we may end up in a Type 2 equilibrium.

Proposition 5 Assume that the fraction of firms with high productivity $(\bar{\pi})$ and the fraction of firms with good signal $(\rho)$ remain constant as the precision of signals $\left(\pi_{g}\right.$ and $\pi_{b}$ ) changes. Then steady state output is increasing in the precision of signals.

Proof. See Appendix B.1.

This Proposition suggests that economies in which good firms are likely to remain good are more productive than economies where firms face a lot of uncertainty about their future productivity. Although the economic success of Japan after WWII is well known, convincing evidence on the extent of uncertainty in the economy at any given point in time is not readily available. However, there is considerable evidence that Japan's human capital was notoriously specific (e.g. see ?), which we now show is consistent with our model in type 1 economies.

Proposition 6 Assume that the fraction of firms with high productivity $(\bar{\pi})$ and the fraction of firms with good signal $(\rho)$ remain constant as the precision of signals $\left(\pi_{g}\right.$ and $\left.\pi_{b}\right)$ changes. In Type 1 economies, where all high productivity firms hire generalists, the fraction of workers investing in specific human capital is increasing in the precision of signals. 
Proof. See Appendix B.2.

Together, our last two Propositions suggest that economies with lower uncertainty tend to have more specific human capital and be more productive than economies with higher uncertainty. However, we will argue in the next section that what makes economies more productive during times of low uncertainty also makes these economies more vulnerable to turbulence.

It should be noted, however, that our last Proposition does not extend to other types of equilibria. For instance, if an increase in the precision of signals moves the economy from Type 3 (where there are no generalists) to Type 2 (where generalists only work in surprisingly good firms), then the fraction of individuals with specific human capital must decrease.

\section{The Impact of Turbulence}

In order to study the impact of turbulence, we introduce an aggregate state which determines the accuracy of signals and takes one of two values: $z \in\{P, N\}$. The environment described in Section 2 corresponds to the precise state $P$, while in the noisy state $N$ signals are completely uninformative: the probability of a firm drawing high productivity is independent of the signal it received. To keep the fraction of high productivity firms $(\bar{\pi})$ unchanged, we set the probability of getting high productivity in the noisy state equal to $\bar{\pi}$ regardless of the signal. Accordingly, one can think of state $N$ as a state of the world in which productivities are re-shuffled across firms while maintaining the same ex post measure of firms with low and high productivity as in state $P$. In that sense, the aggregate technology set remains constant across states.

It should be noted that only Type 1 or Type 3 equilibria can emerge in an economy which expects to remain in state $N$. When signals are completely uninformative, we have $E_{g}=E_{b}=\bar{Z}$. The conditions summarized in Table 1 imply that either $\bar{Z}<\gamma Z_{H}$ and a Type 1 equilibrium emerges, or $\bar{Z}>\gamma Z_{H}$ and we have a Type 3 equilibrium. However, we view Type 1 equilibria as a more plausible and interesting case. This is because type 3 equilibria can only occur if the productivity levels are close to one another and general human capital is sufficiently less productive than specific 
human capital, which means that heterogeneity across firms plays a very minor role in that case. Although we present some results for Type 3 equilibria below, we will concentrate our analysis mainly on Type 1 equilibria.

In the rest of this section we study the effects of two forms of turbulence, where turbulence is defined in a natural way as a drop in the precision of signals. The first one is an expected permanent change in the precision of signals, realized before any investment in human capital has been made. As such, this experiment consists of a regime switch from tranquil to turbulent times. Our second experiment is an unexpected transitory turbulence shock, that is, signals are uninformative for a single period.

\subsection{Expected Permanent Change in Precision of Signals}

Consider an economy which is initially in steady state. In period 0, before any investment decisions have been made, everyone learns that from now on signals no longer contain any information. To determine the effects of this regime switch, we only need to determine how the steady state to which the economy will converge compares to the original steady state. Our convergence results from Section 4.3 imply that the economy will converge smoothly to this new steady state.

Proposition 7 Following a permanent switch to a world in which signals are no longer informative (state $N$ ), the economy converges to a new steady state with lower output. The loss in output is increasing in the precision of signals in the original steady state.

Proof. Recall that the transition to the new steady state is monotone (see Proposition 4). The proof then follows from Proposition 5, which establishes that the steady state value of output is increasing in the precision of signals.

Figure 2 depicts the path of output following a regime switch from tranquil to turbulent times. The path for the measure of firms $\left(\mu_{t}\right)$ mimics that of output. If the initial steady state is of Type 1, this Proposition implies that a regime switch has a larger impact in economies where specific human capital is more predominant. The adjustment to the ratio of specific to general human capital for the young adjusts 
Figure 2: Expected regime switch $(\theta=2 / 3)$

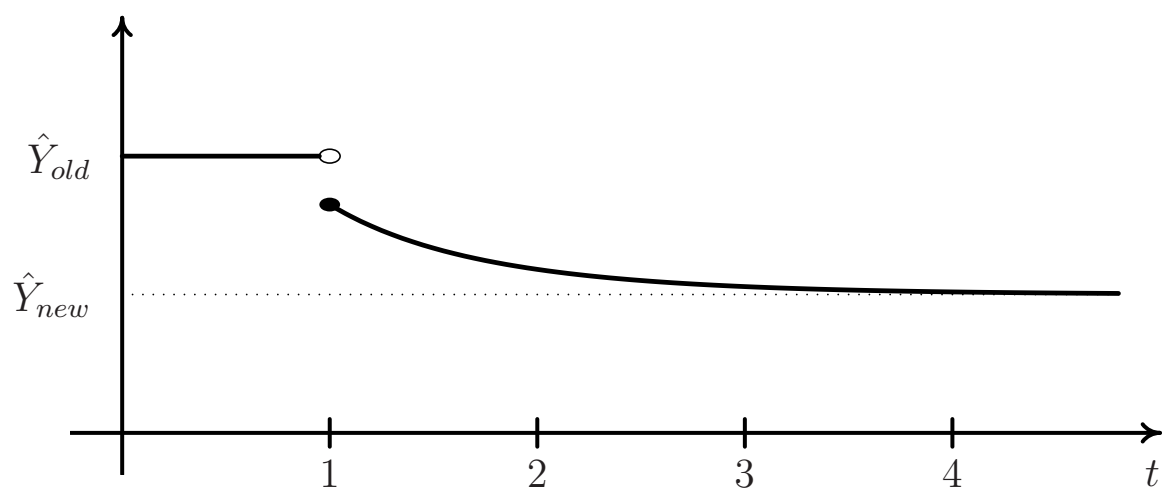

immediately and remains at that new, lower level throughout the transition. This Proposition implies that the impact of turbulence depends in a crucial way on the amount of fundamental uncertainty prior to the regime switch.

\subsection{Unexpected Turbulence Shock}

In the last section we established that an expected regime switch from tranquil to turbulent times sends the economy on a smooth path towards a lower steady state. We now demonstrate that a transient turbulence shock can cause a prolonged period of low output. More importantly, we show that the fewer specialists a Type 1 economy has in the period of the shock, the more resilient it is to transient turbulence shocks. We first establish the intuitive result that output falls in the period of the shock, whether the (unexpected) shock is transitory or permanent.

Proposition 8 An unexpected turbulence shock (transitory or permanent) leads to an immediate decrease in output relative to tranquil times, even though the fraction of firms with high productivity remains constant.

Proof. First, consider an "informed" economy in which the number of entering firms $\mu_{T}$ is the same as in our economy just before the shock, but the shock is foreseen. Since investment in, and the allocation of, human capital in the "informed" economy is efficient, the output in that economy in the period of turbulence is greater than in the economy that was surprised: $Y_{T}^{I} \geqslant Y_{T}^{N}$. 
Second, output in the artificial "informed" economy is smaller than that of the undisturbed economy: $Y_{T}^{I}<Y_{T}^{P}$. To see this, note that, given $\mu_{T}$, output is pinned down by the constant $A$ (equation (13)). In the proof of Proposition 5 (see Appendix B.1), we established that $A$ is strictly increasing in the precision of signals. And since the undisturbed economy has more precise signals than the "informed" one (due to the nature of the turbulence shock), it will produce strictly greater output from the same number of firms. It follows that $Y_{T}^{N}<Y_{T}^{P}$.

Our next Proposition establishes, for Type 1 and Type 3 economies, that the size of the fall is increasing in the precision of signals in tranquil times.

Proposition 9 Assume that the fraction of firms with high productivity $(\bar{\pi})$ and the fraction of firms with good signal $(\rho)$ remain constant as the precision of signals $\left(\pi_{g}\right.$ and $\left.\pi_{b}\right)$ changes. If the economy is initially in a Type 1 or Type 3 equilibrium, then the fraction of output lost following an unexpected transitory turbulence shock is increasing in the precision of signals in tranquil times.

Proof. See Appendix B.3.

Observe that this proposition states that the proportional decrease in output is relative to where the economy would have been without turbulence, not relative to where the economy was last period. In other words, the result holds whether the economy is in or out of steady state prior to the shock.

This Proposition establishes that economies that are initially more productive (see Proposition 5) are also more vulnerable to turbulence shocks. The force that makes economies more productive (specific human capital) is also at the heart of their vulnerability to turbulence, as specific human capital cannot be re-allocated ex post. Note that while this result only involves the intensive margin for Type 3 equilibria, it involves both the intensive and extensive margins for Type 1 equilibria since low uncertainty prior to the shock is conducive to the accumulation of specific human capital in such economies.

In order to determine the path of the economy following an unexpected turbulence shock, we need to know how the (smaller than expected) output is distributed among the generations in the period of the shock, because the amount of investment depends on the income of middle-aged workers. One possible approach is to fulfill the promise 
to either the middle-aged or the old individuals (we cannot fulfill both as the expected output is equal to the sum of these promises). The problem with this approach is that the realized output may not be sufficient to fulfill either one of these promises. The approach we follow is to consider how the output would be allocated if the turbulence shock were not exactly unexpected - we introduce a positive probability of the turbulent state into the original economy (maintaining complete markets) and look at how the output is distributed in the turbulent state. It turns out that the resources are allocated between the middle-aged and old individuals in the same proportions in the two states (normal and turbulent). ${ }^{15}$

Let $\delta$ denote the probability of the aggregate state $z=P$ and let $q_{t}(z)$ denote the price in period $t$ of an Arrow security that pays one unit of consumption good in period $t+1$ contingent on the aggregate state being $z$. Finally, let $Y_{t}^{d}=Y_{t}-c_{t}^{3}$ denote the disposable income of middle-aged workers in period $t$.

Proposition 10 The fractions of total output allocated to old and middle-aged workers are the same in all states:

$$
\frac{c_{t}^{3}(P)}{Y_{t}^{d}(P)}=\frac{c_{t}^{3}(N)}{Y_{t}^{d}(N)}
$$

Proof. See Appendix B.4.

To summarize, Proposition 9 establishes the extent of the initial downturn in the economy. Proposition 10 establishes how resources are distributed among individuals of different ages in the period of the shock, thereby determining the initial conditions for the subsequent convergence which is described in Proposition 4. Figure 3 illustrates the path of output following a transitory turbulence shock.

Notice that in the period of the shock, human capital used in production is fixed from the previous period. Furthermore, since the environment in the period of the shock is the same as it was prior to the shock (other than the measure of firms), entering firms will make the same decisions in terms of human capital investments as

\footnotetext{
${ }^{15}$ If the promise to the old individuals is fulfilled, the magnitude of the shock is magnified following the shock, as the fall in the income of middle-aged people (and hence investment) is disproportionately large. On the other hand, if the promise to the middle aged is fulfilled, the economy completely recovers in the period after the shock, as the investment does not suffer. The "intermediate" case we consider is illustrated in Figure 3.
} 
Figure 3: Unexpected one-time shock $(\theta=2 / 3)$

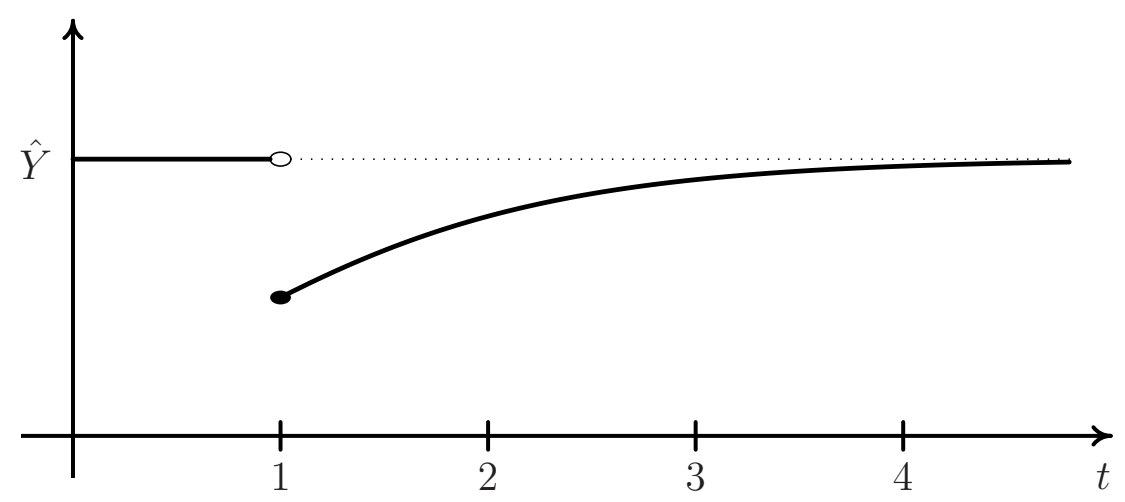

before. Therefore the fraction of individuals with specific and general human capital in the period of the shock and throughout the transition path remains the same as it was prior to the shock. The lower output in the period of the shock is due to the misallocation of labor across firms in that period. The persistence of the shock is due to the fact that lower output translates into a lower measure of firms entering, and so on.

Taken together, the results of this section imply that whereas economies characterized by low volatility tend to have more specific human capital and higher output, they also tend to be more vulnerable to turbulence shocks, which cause prolonged periods of low output. To the extent that the Japanese economy featured low uncertainty prior to a sudden rise in economic volatility, the model is consistent with Japan going through a prolonged stagnation after decades of prosperity. It should be emphasized that conventional productivity measures would attribute the stagnation period to low productivity, despite the fact that the aggregate technology in the model remains unchanged throughout that period. In that sense, the low measured productivity in Japan since the 1990's documented by Hayashi and Prescott (2002) may be due to a lack of reallocation of resources, consistent with the findings of Kawamoto (2004). 


\section{Conclusion}

This paper shows that the choice of specific versus general human capital can lead economies to prosper under tranquil times but also to experience prolong stagnation when hit by turbulence shocks. In turn, the prevalence of specific human capital is largely determined by the extent of uncertainty in tranquil times. We argue that our theory offers a coherent view of Japan's economic experience since WWII.

We also believe that our theory speaks to the experience of a variety of countries in a catching up phase of development. For instance, many countries (including Japan, but also many European countries) after WWII chose a relatively specialized labor force. This choice was made at a time when these countries were relatively far from the world technology leader, and so faced relatively little uncertainty about future profitability as they could use the U.S. as a laboratory. Of course, as our theory implies, a high degree of commitment is needed in order to take advantage of this period of low volatility. Our theory also implies that taking advantage of low volatility periods may involve a lack of reallocation which propels the economy into a prolong stagnation if hit by a turbulence shock.

The previous paragraph also points to an important caveat of this paper: what differentiates countries in our model is the extent of uncertainty in the economy, for which convincing evidence is hard to find. An obvious starting point could be to investigate the persistence of profits over time in different economies. Such measures, however, are highly problematic. In particular, our model does not imply that profits are more volatile in turbulent times relative to tranquil times. ${ }^{16}$ The reason is that the composition of the labor force changes in such a way as to mitigate the impact of uncertainty. As an extreme case, our model implies that economies in which the labor force is predominately composed of generalists are largely immune to turbulence. We view the fact that Japan's human capital is notoriously specific as evidence that uncertainty was low in Japan prior to the recent turbulent episode.

\footnotetext{
${ }^{16}$ Indeed, Odagiri and Yamawaki (1986) present mixed evidence on the persistent of profits in the U.S. versus Japan.
} 


\section{A Equilibria: Details}

Since all types of equilibrium are very similar, we only present in detail how to construct an equilibrium for one of these cases. For the other cases, we only present the value of the constant $A$, which is sufficient to construct an equilibrium as shown in Section 4.

\section{A.1 Type 1: All High Productivity Firms Hire Generalists}

\section{A.1.1 Middle-Aged Firms' Problems}

There are four (4) types of middle-aged firms: firms who received a good signal when young can either have a high or low productivity level, and similarly for firms who received a bad signal.

Good Signal $(s=g)$, High Productivity $\left(Z=Z_{H}\right)$ Firms who received a good signal when young decided to hire and train $H(g)$ individuals in specific human capital. Their problem when middle-aged is as follows:

$$
R\left(Z_{H}, H(g)\right) \equiv \max _{G \geqslant 0}\left\{Z_{H}(H(g)+\gamma G)^{\theta}-w^{G} G\right\},
$$

where $w^{G}$ is the wage rate of generalists and $G$ is the number of generalists to be hired. Optimality implies that

$$
w^{G}=\theta Z_{H} \gamma(H(g)+\gamma G)^{\theta-1},
$$

and the number of generalists to hire is given by ${ }^{17}$

$$
G(g)=\frac{1}{\gamma}\left[\left(\frac{\gamma \theta Z_{H}}{w^{G}}\right)^{\frac{1}{1-\theta}}-H(g)\right] .
$$

The revenue function for these firms is therefore given by

$$
\begin{aligned}
R\left(Z_{H}, H(g)\right) & =Z_{H}\left(\frac{\gamma \theta Z_{H}}{w^{G}}\right)^{\frac{\theta}{1-\theta}}-\frac{w^{G}}{\gamma}\left[\left(\frac{\gamma \theta Z_{H}}{w^{G}}\right)^{\frac{1}{1-\theta}}-H(g)\right] \\
& =(1-\theta) Z_{H}\left(\frac{\gamma \theta Z_{H}}{w^{G}}\right)^{\frac{\theta}{1-\theta}}+\frac{w^{G}}{\gamma} H(g) .
\end{aligned}
$$

\footnotetext{
${ }^{17}$ Since firms with low productivity do not hire generalists, it should be clear that $G(g)$ denotes the number of generalists hired by firms who received a good signal (and a high productivity level).
} 
Good Signal $(s=g)$, Low Productivity $\left(Z=Z_{L}\right) \quad$ Although these firms have a low realized productivity, they still received a good signal when young and thus also decided to hire and train $H(g)$ individuals. Since these firms will definitely not hire generalists (they would want to get rid of some of their specialists, so $G=0$ for these firms), their revenue function when middle-aged is given by

$$
R\left(Z_{L}, H(g)\right) \equiv Z_{L} H(g)^{\theta}
$$

Bad Signal $(s=b)$, High Productivity $\left(Z=Z_{H}\right)$ Firms who received a bad signal when young decided to hire and train $H(b)$ individuals in specific human capital. Their problem when middle-aged is as follows:

$$
R\left(Z_{H}, H(b)\right) \equiv \max _{G \geqslant 0}\left\{Z_{H}(H(b)+\gamma G)^{\theta}-w^{G} G\right\} .
$$

Optimality implies that

$$
w^{G}=\theta Z_{H} \gamma(H(b)+\gamma G)^{\theta-1},
$$

and the number of generalists to hire in this case is given by ${ }^{18}$

$$
G(b)=\frac{1}{\gamma}\left[\left(\frac{\gamma \theta Z_{H}}{w^{G}}\right)^{\frac{1}{1-\theta}}-H(b)\right],
$$

so their revenue function is given by

$$
R\left(Z_{H}, H(b)\right)=(1-\theta) Z_{H}\left(\frac{\gamma \theta Z_{H}}{w^{G}}\right)^{\frac{\theta}{1-\theta}}+\frac{w^{G}}{\gamma} H(b) .
$$

Bad Signal $(s=b)$, Low Productivity $\left(Z=Z_{L}\right)$ These firms realized a low productivity after getting a bad signal, so they hired $H(b)$ specialists and will not hire any generalists $(G=0)$, so their revenue function when middle-aged is given by

$$
R\left(Z_{L}, H(b)\right) \equiv Z_{L} H(b)^{\theta}
$$

From equations (27) and (29), we get the following relationship between high productivity firms' hiring decisions:

$$
H(g)-H(b)=\gamma[G(b)-G(g)]
$$

\footnotetext{
${ }^{18}$ Since firms with low productivity do not hire generalists, it should be clear that $G(b)$ denotes the number of generalists hired by firms who received a bad signal (and a high productivity level).
} 


\section{A.1.2 Young Firms' Problems}

There are two types of young firms: those with a good signal and those with a bad signal. Both types of firms need to make a hiring decision when young based on their expected profits when middle-aged.

Good signal $(s=g)$ The problem for firms who receive a good signal is as follows:

$$
\max _{H}\left\{\pi_{g} R\left(Z_{H}, H\right)+\left(1-\pi_{g}\right) R\left(Z_{L}, H\right)-w^{H} H\right\},
$$

where $w^{H}$ is the wage rate per unit of firm specific human capital. Optimality thus requires that

$$
w^{H}=\pi_{g} \frac{w^{G}}{\gamma}+\left(1-\pi_{g}\right) \theta Z_{L} H^{\theta-1}
$$

which means that

$$
H(g)=\left(\frac{\gamma\left(1-\pi_{g}\right) \theta Z_{L}}{\gamma w^{H}-\pi_{g} w^{G}}\right)^{\frac{1}{1-\theta}}
$$

Bad signal $(s=b)$ The problem for firms who receive a bad signal when young is as follows:

$$
\max _{H}\left\{\pi_{b} R\left(Z_{H}, H\right)+\left(1-\pi_{b}\right) R\left(Z_{L}, H\right)-w^{H} H\right\} .
$$

Optimality thus requires that

$$
w^{H}=\pi_{b} \frac{w^{G}}{\gamma}+\left(1-\pi_{b}\right) \theta Z_{L} H^{\theta-1}
$$

which means that

$$
H(b)=\left(\frac{\gamma\left(1-\pi_{b}\right) \theta Z_{L}}{\gamma w^{H}-\pi_{b} w^{G}}\right)^{\frac{1}{1-\theta}} .
$$

Notice that by replacing the expression for $H(g)$ (equation (31)) into the expression for $G(g)$ (equation (28)), we have

$$
G(g)=\frac{(\gamma \theta)^{\frac{1}{1-\theta}}}{\gamma}\left[\left(\frac{Z_{H}}{w^{G}}\right)^{\frac{1}{1-\theta}}-\left(\frac{\left(1-\pi_{g}\right) Z_{L}}{\gamma w^{H}-\pi_{g} w^{G}}\right)^{\frac{1}{1-\theta}}\right],
$$

which is strictly positive if $\gamma>\pi_{g}$ and the following condition holds: ${ }^{19}$

$$
\frac{Z_{H}}{Z_{L}}>\frac{1-\pi_{g}}{\gamma-\pi_{g}}
$$

\footnotetext{
${ }^{19}$ This condition corresponds to equation (20) in the main text.
} 
that is, this type of equilibrium occurs if (i) high productivity firms are sufficiently more productive than low productivity firms, (ii) the probability of getting high productivity conditional on having received a good signal is not too high, and (iii) if the productivity of general human capital (relative to specific human capital) is sufficiently high. Another way to write the previous expression is as follows:

$$
\gamma Z_{H}>E[Z \mid s=g]=E_{g}
$$

which simply says that the good productivity level is sufficiently high and sufficiently productive relative to expected productivity once a firm knows her signal.

Similarly, by replacing the expression for $H(b)$ (equation (32)) into the expression for $G(b)$ (equation (30)), we can see that $G(b)$ will be strictly positive if $\gamma>\pi_{b}$ and the following condition holds: ${ }^{20}$

$$
\frac{Z_{H}}{Z_{L}}>\frac{1-\pi_{b}}{\gamma-\pi_{b}}
$$

which means that when this condition is not satisfied, there will be no generalists in equilibrium.

\section{A.1.3 Labor Market Clearing Condition}

The global labor market clearing condition is that the total number of workers hired adds up to unity. Since a fraction $\rho$ of firms, of which there are a total of $\mu$, receive a good signal and hire $H(g)$ individuals, and similarly for firms who receive a bad signal, the labor market clearing condition for specialists (equation (5)) states that

$$
1-M=\mu \rho H(g)+\mu(1-\rho) H(b) .
$$

Similarly, middle-aged firms with good signals who's productivity turns out to be high $\left(\rho \pi_{g}\right)$ hire $G(g)$ generalists, and similarly for firms with bad signals, so that the labor market clearing condition for generalists (equation (4)) simplifies to

$$
M=\mu \rho \pi_{g} G(g)+\mu(1-\rho) \pi_{b} G(b) .
$$

\footnotetext{
${ }^{20}$ This condition corresponds to equation (21) in the main text.
} 
Adding up these two labor market clearing conditions, we have

$$
\begin{aligned}
\mu \rho\left(\frac{\gamma\left(1-\pi_{g}\right) \theta Z_{L}}{\gamma w^{H}-\pi_{g} w^{G}}\right)^{\frac{1}{1-\theta}} & +\mu(1-\rho)\left(\frac{\gamma\left(1-\pi_{b}\right) \theta Z_{L}}{\gamma w^{H}-\pi_{b} w^{G}}\right)^{\frac{1}{1-\theta}} \\
+\mu \rho \pi_{g} \frac{1}{\gamma} & {\left[\left(\frac{\gamma \theta Z_{H}}{w^{G}}\right)^{\frac{1}{1-\theta}}-\left(\frac{\gamma\left(1-\pi_{g}\right) \theta Z_{L}}{\gamma w^{H}-\pi_{g} w^{G}}\right)^{\frac{1}{1-\theta}}\right] } \\
+ & \mu(1-\rho) \pi_{b} \frac{1}{\gamma}\left[\left(\frac{\gamma \theta Z_{H}}{w^{G}}\right)^{\frac{1}{1-\theta}}-\left(\frac{\gamma\left(1-\pi_{b}\right) \theta Z_{L}}{\gamma w^{H}-\pi_{b} w^{G}}\right)^{\frac{1}{1-\theta}}\right]=1,
\end{aligned}
$$

which, since $w^{H}=w^{G}=w_{t}$, simplifies to

$$
\begin{array}{r}
\mu\left(\frac{\theta}{w_{t}}\right)^{\frac{1}{1-\theta}}\left\{\rho\left(\frac{\gamma\left(1-\pi_{g}\right) Z_{L}}{\gamma-\pi_{g}}\right)^{\frac{1}{1-\theta}}+(1-\rho)\left(\frac{\gamma\left(1-\pi_{b}\right) Z_{L}}{\gamma-\pi_{b}}\right)^{\frac{1}{1-\theta}}\right. \\
+\rho \pi_{g} \frac{1}{\gamma}\left[\left(\gamma Z_{H}\right)^{\frac{1}{1-\theta}}-\left(\frac{\gamma\left(1-\pi_{g}\right) Z_{L}}{\gamma-\pi_{g}}\right)^{\frac{1}{1-\theta}}\right] \\
\left.+(1-\rho) \pi_{b} \frac{1}{\gamma}\left[\left(\gamma Z_{H}\right)^{\frac{1}{1-\theta}}-\left(\frac{\gamma\left(1-\pi_{b}\right) Z_{L}}{\gamma-\pi_{b}}\right)^{\frac{1}{1-\theta}}\right]\right\}=1,
\end{array}
$$

and we get

$$
w_{t}=\theta A \mu_{t}^{1-\theta}
$$

where $A$ is defined by

$$
\begin{aligned}
A=\{\rho[ & \left.\pi_{g} Z_{H}\left(\gamma Z_{H}\right)^{\frac{\theta}{1-\theta}}+\left(1-\pi_{g}\right) Z_{L}\left(\frac{\gamma\left(1-\pi_{g}\right) Z_{L}}{\gamma-\pi_{g}}\right)^{\frac{\theta}{1-\theta}}\right] \\
& \left.+(1-\rho)\left[\pi_{b} Z_{H}\left(\gamma Z_{H}\right)^{\frac{\theta}{1-\theta}}+\left(1-\pi_{b}\right) Z_{L}\left(\frac{\gamma\left(1-\pi_{b}\right) Z_{L}}{\gamma-\pi_{b}}\right)^{\frac{\theta}{1-\theta}}\right]\right\}^{1-\theta} .
\end{aligned}
$$

\section{A.2 Type 2: Only High Productivity Firms with Bad Signals Hire Generalists}

The only difference with the previous section is that $G(g)=0$. It follows that the constant $A$ implied by the labor market clearing condition is now defined as

$$
A=\left\{\rho E_{g}^{\frac{1}{1-\theta}}+(1-\rho)\left[\pi_{b} Z_{H}\left(\gamma Z_{H}\right)^{\frac{\theta}{1-\theta}}+\left(1-\pi_{b}\right) Z_{L}\left(\frac{\gamma\left(1-\pi_{b}\right) Z_{L}}{\gamma-\pi_{b}}\right)^{\frac{\theta}{1-\theta}}\right]\right\}^{1-\theta} .
$$




\section{A.3 Type 3: All Individuals are Specialists}

The only difference with Type 1 economies is that $G(g)=G(b)=0$. It follows that the constant $A$ implied by the labor market clearing condition is now defined as

$$
A=\left(\rho E_{g}^{\frac{1}{1-\theta}}+(1-\rho) E_{b}^{\frac{1}{1-\theta}}\right)^{1-\theta}
$$

\section{A.4 Special Case of Type 1: All Individuals are Generalists}

Finally, in this special case, we have

$$
A=\left(\bar{\pi}\left(\gamma^{\theta} Z_{H}\right)^{\frac{1}{1-\theta}}+(1-\bar{\pi})\left(\gamma^{\theta} Z_{L}\right)^{\frac{1}{1-\theta}}\right)^{1-\theta} .
$$

Note that this expression simplifies further as $Z_{L}=0$ is a necessary condition for this type of equilibrium to occur.

\section{B Proofs}

The exercise in the following propositions is to increase $\pi_{g}$ and decrease $\pi_{b}$, keeping $\rho$ constant, so that the fraction of firms with high productivity, $\bar{\pi}=\rho \pi_{g}+(1-\rho) \pi_{b}$, is unchanged. That is, $\pi_{b}=\frac{\bar{\pi}-\rho \pi_{g}}{1-\rho}$. The nature of the exercise allows us to employ the following result:

Lemma 3 If $f$ is strictly convex and $\pi_{b}=\frac{\bar{\pi}-\rho \pi_{g}}{1-\rho}$, then the function $\rho f\left(\pi_{g}\right)+(1-$ $\rho) f\left(\pi_{b}\right)$ is increasing in $\pi_{g}$ whenever $\pi_{g}>\pi_{b}$.

Proof. The proof follows by simply replacing the formula for $\pi_{b}$ into the function and taking the derivative.

\section{B.1 Proof of Proposition 5}

We need to show that the value of $A$ is strictly increasing in the precision of the signals (see equation (26)). It will be convenient to define $D=A^{\frac{1}{1-\theta}}$ and show that $D$ is strictly increasing in the precision of the signals. We have three cases to consider, depending on the type of equilibrium under consideration. 
Type 1: All firms with high productivity hire extra general human capital. ${ }^{21}$ This is the case when $E_{g}<\gamma Z_{H}$. Note that this implies $\gamma>\pi_{g} \geqslant \pi_{b}$. The formula for $D$ come from equation (33). Differentiating with respect to $\pi_{g}$ and recalling that $\frac{d \pi_{b}}{d \pi_{g}}=-\frac{\rho}{1-\rho}$, we get

$$
\frac{d D}{d \pi_{g}}=\frac{\rho \gamma^{\frac{\theta}{1-\theta}} Z_{L}^{\frac{1}{1-\theta}}}{(1-\theta)}\left[\left(\frac{1-\pi_{g}}{\gamma-\pi_{g}}\right)^{\frac{\theta}{1-\theta}}\left(\theta \frac{1-\pi_{g}}{\gamma-\pi_{g}}-1\right)-\left(\frac{1-\pi_{b}}{\gamma-\pi_{b}}\right)^{\frac{\theta}{1-\theta}}\left(\theta \frac{1-\pi_{b}}{\gamma-\pi_{b}}-1\right)\right] .
$$

Define the functions $g(p)=\frac{1-p}{\gamma-p}$ and $f(p)=g(p)^{\frac{\theta}{1-\theta}}(\theta g(p)-1)$ and note that $\frac{d D}{d \pi_{g}}=$ $\frac{\frac{\rho}{\frac{\theta}{1-\theta}} Z_{L}^{\frac{1}{1-\theta}}}{(1-\theta)}\left(f\left(\pi_{g}\right)-f\left(\pi_{b}\right)\right)$. To show that the value of $D$ is strictly increasing in the precision of signals, we need to show that $f\left(\pi_{g}\right)-f\left(\pi_{b}\right)>0$. This follows from the facts that $\pi_{g}>\pi_{b}$ and that $f$ is strictly increasing on $\left[\pi_{b}, \pi_{g}\right]$. To establish the latter, recall that $\gamma>\pi_{g}$, which implies that $f$ is differentiable on the relevant interval.

$$
f^{\prime}(p)=\frac{\theta}{1-\theta} g(p)^{\frac{\theta}{1-\theta}} \frac{(1-\gamma)^{2}}{(1-p)(\gamma-p)^{2}}>0
$$

Type 2: Only firms with bad signals but high productivity hire extra general human capital. This is the case when $E_{b}<\gamma Z_{H} \leqslant E_{g}$. Note that this implies $\frac{Z_{H}}{Z_{L}}>\frac{1-\pi_{b}}{\gamma-\pi_{b}}$. The formula for $D$ in this case comes from equation (34). Taking the derivative with respect to $\pi_{g}$ and recalling that $\frac{d E_{g}}{d \pi_{g}}=Z_{H}-Z_{L}$, we get

$$
\frac{d D}{d \pi_{g}}=\rho E_{g}^{\frac{\theta}{1-\theta}} \frac{Z_{H}-Z_{L}}{1-\theta}-\rho \gamma^{\frac{\theta}{1-\theta}} Z_{H}^{\frac{1}{1-\theta}}-\frac{\rho \gamma^{\frac{\theta}{1-\theta}} Z_{L}^{\frac{1}{1-\theta}}}{1-\theta}\left(\frac{1-\pi_{b}}{\gamma-\pi_{b}}\right)^{\frac{\theta}{1-\theta}}\left(\theta \frac{1-\pi_{b}}{\gamma-\pi_{b}}-1\right) .
$$

Since $E_{g} \geqslant \gamma Z_{H}$,

$$
\frac{d D}{d \pi_{g}} \geqslant \frac{\rho \gamma^{\frac{\theta}{1-\theta}} Z_{L}^{\frac{1}{1-\theta}}}{1-\theta}\left[\left(\frac{Z_{H}}{Z_{L}}\right)^{\frac{\theta}{1-\theta}}\left(\theta \frac{Z_{H}}{Z_{L}}-1\right)-\left(\frac{1-\pi_{b}}{\gamma-\pi_{b}}\right)^{\frac{\theta}{1-\theta}}\left(\theta \frac{1-\pi_{b}}{\gamma-\pi_{b}}-1\right)\right]
$$

Define the function $h(x)=x^{\frac{\theta}{1-\theta}}(\theta x-1)$ and note that $\frac{d D}{d \pi_{g}}=\frac{\rho \gamma^{\frac{\theta}{1-\theta}} Z_{L}^{\frac{1}{1-\theta}}}{1-\theta}\left(h\left(\frac{Z_{H}}{Z_{L}}\right)-h\left(\frac{1-\pi_{b}}{\gamma-\pi_{b}}\right)\right)$. So, to show that the value of $D$ is strictly

\footnotetext{
${ }^{21}$ The special case in which everyone invests in general human capital only is trivial: a decrease in the precision of the signal has no effect.
} 
increasing in the precision of the signals, we need to show that $h\left(\frac{Z_{H}}{Z_{L}}\right)-h\left(\frac{1-\pi_{b}}{\gamma-\pi_{b}}\right)>0$. This follows from the facts that $\frac{Z_{H}}{Z_{L}}>\frac{1-\pi_{b}}{\gamma-\pi_{b}}$ and that $h$ is strictly increasing on $[1,+\infty)$ :

$$
h^{\prime}(x)=\frac{\theta g(x)^{\frac{\theta}{1-\theta}}}{(1-\theta) x}(x-1) \text {. }
$$

Type 3: Everyone invests in specific human capital only. The formula for $D$ then comes from equation (35).

$$
\frac{d D}{d \pi_{g}}=\frac{\rho\left(Z_{H}-Z_{L}\right)}{1-\theta}\left(E_{g}^{\frac{\theta}{1-\theta}}-E_{b}^{\frac{\theta}{1-\theta}}\right)>0 .
$$

\section{B.2 Proof of Proposition 6}

We will show that the ratio of the stocks of specific and general human capital $\frac{\mathcal{H}}{\mathcal{G}}=$ $\frac{\rho H(g)+(1-\rho) H(b)}{\rho \pi_{g} G(g)+(1-\rho) \pi_{b} G(b)}$ is increasing in the precision of signals. Please refer to Appendix A.1 for derivations of underlying formulae.

When all high productivity firms hire generalists, equations (31) and (32) apply, and the total stock of specific human capital is given by

$$
\mathcal{H}=\left(\frac{\gamma \theta Z_{L}}{w}\right)^{\frac{1}{1-\theta}}\left(\rho\left(\frac{1-\pi_{g}}{\gamma-\pi_{g}}\right)^{\frac{1}{1-\theta}}+(1-\rho)\left(\frac{1-\pi_{b}}{\gamma-\pi_{b}}\right)^{\frac{1}{1-\theta}}\right)
$$

Using equations (28) and (30), we get the total stock of general human capital:

$\mathcal{G}=\frac{1}{\gamma}\left[\bar{\pi}\left(\frac{\gamma \theta Z_{H}}{w}\right)^{\frac{1}{1-\theta}}-\left(\frac{\gamma \theta Z_{L}}{w}\right)^{\frac{1}{1-\theta}}\left(\rho \pi_{g}\left(\frac{1-\pi_{g}}{\gamma-\pi_{g}}\right)^{\frac{1}{1-\theta}}+(1-\rho) \pi_{b}\left(\frac{1-\pi_{b}}{\gamma-\pi_{b}}\right)^{\frac{1}{1-\theta}}\right)\right]$

Taking the ratio,

$$
\frac{\mathcal{H}}{\mathcal{G}}=\frac{\gamma Z_{L}^{\frac{1}{1-\theta}}\left(\rho\left(\frac{1-\pi_{g}}{\gamma-\pi_{g}}\right)^{\frac{1}{1-\theta}}+(1-\rho)\left(\frac{1-\pi_{b}}{\gamma-\pi_{b}}\right)^{\frac{1}{1-\theta}}\right)}{\theta Z_{H}^{\frac{1}{1-\theta}}-Z_{L}^{\frac{1}{1-\theta}}\left(\rho \pi_{g}\left(\frac{1-\pi_{g}}{\gamma-\pi_{g}}\right)^{\frac{1}{1-\theta}}+(1-\rho) \pi_{b}\left(\frac{1-\pi_{b}}{\gamma-\pi_{b}}\right)^{\frac{1}{1-\theta}}\right)}
$$

Define the following functions: $f(x)=\left(\frac{1-x}{\gamma-x}\right)^{\frac{1}{1-\theta}}$ and $g(x)=x f(x)$. Both functions are strictly convex on $(-\infty, \gamma)$. Applying Lemma 3, we conclude that the numerator of the ratio is increasing and the denominator of the ratio is decreasing in $\pi_{g}$. Thus, the ratio of specialists to generalists is increasing in the precision of signals when all high productivity firms hire generalists (Type 1 ). 


\section{B.3 Proof of Proposition 9}

\section{B.3.1 Initial equilibrium is Type 1}

Consider two economies, $A$ and $B$, both of Type 1 , with the same fraction of firms receiving signal $g$ and the same fraction of firms receiving productivity $Z_{H}$. Assume that signals are more precise in economy $A$, that is, $\pi_{g}^{A}>\pi_{g}^{B}$ and $\pi_{b}^{A}<\pi_{b}^{B}$. We need to show that the proportional drop in output following an unexpected turbulence shock is greater in economy $A$ than in economy $B$. We know from Proposition 5 that output in tranquil times is higher in economy $A$. We will show that output following an unexpected turbulence shock is lower in economy $A$, which implies that the fall is greater in economy $A$.

Consider additionally the "informed" economy I (see the proof of Proposition 8), where agents knew that signals were uninformative ahead of time (and allocated investment and labor accordingly). Note that economy $I$ is also of type 1 , and we can apply equations (31) and (32) to show $\frac{H_{g}^{A}}{H_{b}^{A}}>\frac{H_{g}^{B}}{H_{b}^{B}}>\frac{H_{g}^{I}}{H_{b}^{I}}=1$, where $H_{s}^{E}$ is the total amount of specific human capital in firms with signals $s$ in economy $E$. Further, Proposition 6 implies that $\mathcal{H}^{A}>\mathcal{H}^{B}>\mathcal{H}^{I}$ and $\mathcal{G}^{A}<\mathcal{G}^{B}<\mathcal{G}^{I}$, where $\mathcal{H}$ and $\mathcal{G}$ are the total stocks of specific and general human capital respectively. By construction, the allocation of investment and labor is optimal in economy $I$. This implies that both misallocation of investment (specific vs general) and misallocation of labor $\left(H_{g}\right.$ vs $H_{b}$ ) are greater in economy $A$ than in economy $B$.

We now simply need to show that (1) given any allocation of investment, output is decreasing in misallocation of labor (Step 1 below); and (2) given any (proportional) allocation of labor, output is decreasing in misallocation of investment (Step 2 below).

Step 1: Given $\mathcal{G}$ and $\mathcal{H}$, output following the unexpected turbulence shock is decreasing in the misallocation of labor $\frac{H_{g}}{H_{b}}$. The exercise is to increase $H_{g}$ while keeping $\mathcal{H}$ constant (this implies $H_{b}=\frac{\mathcal{H}-\mu \rho H_{g}}{\mu(1-\rho)}$ ). Since the number of high productivity firms with bad signals is higher than expected, we have to consider Type 1 as well as Type 2 economies. 
Type 1: Output per firm following the shock is

$$
\begin{aligned}
\frac{Y^{N}}{\mu}=\bar{\pi} \rho Z_{H}\left(H_{g}+\gamma G_{g}^{N}\right)^{\theta}+\bar{\pi}(1-\rho) & Z_{H}\left(H_{b}+\gamma G_{b}^{N}\right)^{\theta} \\
& +(1-\bar{\pi}) \rho Z_{L} H_{g}^{\theta}+(1-\bar{\pi})(1-\rho) Z_{L} H_{b}^{\theta}
\end{aligned}
$$

Note that in this case all high productivity firms employ the same amount of human capital $L=H_{g}+\gamma G_{g}^{N}=H_{b}+\gamma G_{b}^{N}$. Further, since $\bar{\pi} \mu L=\bar{\pi} \mathcal{H}+\gamma \mathcal{G}$ and both $\mathcal{H}$ and $\mathcal{G}$ are fixed, the value of $L$ is independent from the extent of misallocation of labor. Hence, we only need to consider the last two terms in (37), and Lemma 3 guarantees that output following the unexpected turbulence shock is decreasing in misallocation of labor.

Type 2: Output per firm following the shock is

$$
\frac{Y^{N}}{\mu}=\bar{\pi} \rho Z_{H} H_{g}^{\theta}+\bar{\pi}(1-\rho) Z_{H}\left(H_{b}+\gamma G_{b}^{N}\right)^{\theta}+(1-\bar{\pi}) \rho Z_{L} H_{g}^{\theta}+(1-\bar{\pi})(1-\rho) Z_{L} H_{b}^{\theta}
$$

Simply taking derivative with respect to $H_{g}$ (recalling that $\frac{d H_{b}}{d H_{g}}=\frac{-\rho}{1-\rho}$ ) confirms that output is decreasing in misallocation of labor.

Step 2: Keeping $\frac{H_{g}}{H_{b}}$ constant, output following the unexpected turbulence shock is decreasing in misallocation of investment. We will establish that output per firm following the shock is concave in $\mathcal{G}$ (keeping $\mathcal{G}+\mathcal{H}$ constant). Since economy $B$ has too few generalists, and economy $A$ has even fewer, this implies that economy $A$ will produce less output than economy $B$ following the shock (even if it had the same $\frac{H_{g}}{H_{b}}$ as economy $B)$.

Again, we need to consider both Type 1 and Type 2 economies. Differentiating equations (37) and (38) twice with respect to $\mathcal{G}$ establishes the desired concavity in both cases.

\section{B.3.2 Initial equilibrium is Type 3}

The amount of output produced in the 'precise' state is

$$
Y^{P}=A \mu^{1-\theta}
$$


where $A=\left(\rho E_{g}^{\frac{1}{1-\theta}}+(1-\rho) E_{b}^{\frac{1}{1-\theta}}\right)^{1-\theta}$. If, unexpectedly, signals become completely uninformative ex post, then total output produced is

$$
Y^{N}=\frac{\mu^{1-\theta}}{A^{\frac{\theta}{1-\theta}}}\left(\bar{\pi} Z_{H}+(1-\bar{\pi}) Z_{L}\right)\left(\rho E_{g}^{\frac{\theta}{1-\theta}}+(1-\rho) E_{b}^{\frac{\theta}{1-\theta}}\right) .
$$

The proportional decrease in output in the period of an unexpected "noise shock" is

$$
\frac{Y^{P}-Y^{N}}{Y^{N}}=\rho(1-\rho) \frac{\left(Z_{H}-Z_{L}\right)\left(\pi_{g}-\pi_{b}\right)}{\bar{\pi} Z_{H}+(1-\bar{\pi}) Z_{L}} \cdot \frac{E_{g}^{\frac{\theta}{1-\theta}}-E_{b}^{\frac{\theta}{1-\theta}}}{\rho E_{g}^{\frac{\theta}{1-\theta}}+(1-\rho) E_{b}^{\frac{\theta}{1-\theta}}} .
$$

Differentiating equation (39) with respect to $\pi_{g}$ shows that both fractions are increasing in $\pi_{g}$. Accordingly, the extent of damage (decrease in output) is greater in economies with higher expected precision of signals. Intuitively, a higher expected precision of signals increases output in the precise state $\left(Y^{P}\right)$ and decreases output in the non-precise state $\left(Y^{N}\right)$, thus making the extent of damage greater in economies

with higher expected precision. Note that this result implies that $\frac{Y^{P}-Y^{N}}{Y^{P}}$ is also increasing in the precision of signals.

\section{B.4 Proof of Proposition 10}

Utility maximization by middle-aged workers implies the following state-contingent savings:

$$
\begin{aligned}
q_{t-1}(P) c_{t}^{3}(P) & =\frac{\delta \beta}{1+\beta} Y_{t-1}^{d}, \\
q_{t-1}(N) c_{t}^{3}(N) & =\frac{(1-\delta) \beta}{1+\beta} Y_{t-1}^{d},
\end{aligned}
$$

so that

$$
\frac{c_{t}^{3}(P)}{c_{t}^{3}(N)}=\frac{\delta}{1-\delta} \frac{q_{t-1}(N)}{q_{t-1}(P)}
$$

Similarly, utility maximization of young workers in period $t-1$ implies that

$$
\begin{aligned}
q_{t-1}(P) Y_{t}^{d}(P) & =\frac{\left(\beta+\beta^{2}\right) \delta}{1+\beta+\beta^{2}} W_{t-1}, \\
q_{t-1}(N) Y_{t}^{d}(N) & =\frac{\left(\beta+\beta^{2}\right)(1-\delta)}{1+\beta+\beta^{2}} W_{t-1},
\end{aligned}
$$


where $W_{t}$ denotes the present value of lifetime income of young individuals born in period $t$. It follows that

$$
\frac{Y_{t}^{d}(P)}{Y_{t}^{d}(N)}=\frac{\delta}{1-\delta} \frac{q_{t-1}(N)}{q_{t-1}(P)} .
$$

The statement of the Proposition follows from equations (40) and (41). 


\section{References}

Becker, G. (1964). Human Capital. Chicago: The University of Chicago Press.

Caballero, R. J., T. Hoshi, and A. K. Kashyap (2005). Zombie lending and depressed restructuring in Japan. Unpublished manuscript.

Coleman, W. J. (2005). Accommodating emerging giants. Unpublished manuscript.

Comin, D. and T. Philippon (2005). The rise in firm-level volatility: Causes and consequences. In M. Gertler and K. Rogoff (Eds.), NBER Macroeconomics Annual 2005, Volume 20.

den Haan, W., C. Haefke, and G. Ramey (2005). Turbulence and unemployment in a job matching model. Journal of the European Economic Association 3(4), 1360-1385.

Dixit, A. K. and R. S. Pindyck (1994). Investment under Uncertainty. Princeton: Princeton University Press.

Gervais, M. and I. Livshits (2007). Uncertainty, specificity and commitment. Unpublished manuscript.

Hayashi, F. and E. C. Prescott (2002). The 1990s in Japan: A lost decade. Review of Economic Dynamics 5(1), 206-235.

Higuchi, Y. and M. Hashimoto (2004). Issues facing the japanese labor market. Unpublished Manuscript.

Hoshi, T. and A. K. Kashyap (2004). Japan's financial crisis and economic stagnation. Journal of Economic Perspectives 18(1), 3-26.

Kawamoto, T. (2004). What do the purified solow residuals tell us about Japan's lost decade? IMES Discussion Paper No. 2004-E-5.

Krueger, D. and K. B. Kumar (2004). Skill-specific rather than general education: A reason for US-Europe growth differences? Journal of Economic Growth 9(2), $167-207$. 
Ljungqvist, L. and T. J. Sargent (1998). The European unemployment dilemma. Journal of Political Economy 106(3), 514-550.

Ljungqvist, L. and T. J. Sargent (2004). European unemployment and turbulence revisited in a matching model. Journal of the European Economic Association 2(23), 456-467.

Odagiri, H. and H. Yamawaki (1986). A study of company profit-rate time series: Japan and the United States. International Journal of Industrial Organization 4, $1-23$.

Porter, M. E. and M. Sakakibara (2004). Competition in Japan. Journal of Economic Perspectives 18(1), 27-50.

Wasmer, E. (2004). Interpreting European and US labour market differences: The specificity of human capital investments. American Economic Review 96(3), 811831. 